American Journal of Environmental Sciences 4 (6): 683-692, 2008

ISSN $1553-345 \mathrm{X}$

(C) 2008 Science Publications

\title{
Calibration and Simultaneous Monitoring of Soil Water Content and Salinity with Capacitance and Four-electrode Probes
}

\author{
${ }^{1}$ Tadaomi Saito, ${ }^{2}$ Haruyuki Fujimaki and ${ }^{1}$ Mitsuhiro Inoue \\ ${ }^{1}$ Arid Land Research Center and Tottori University, 1390 Hamasaka, Tottori 680-0001, Japan \\ ${ }^{2}$ Graduate School of Life and Environmental Sciences, University of Tsukuba, \\ 1-1-1 Tennodai, Tsukuba, Ibaraki 305-8572, Japan
}

\begin{abstract}
Non-destructive monitoring of soil water content (W) and the electrical conductivity of the soil solution $(\mathrm{ECw})$ has been desired for environmental evaluation and sustainable agriculture. Dielectric probes and four-electrode probes are widely used for the non-destructive determination of W and the soil bulk electrical conductivity $(\mathrm{ECb})$, respectively. Since the output of dielectric probes is affected by soil salinity, the calibration for the effect is indispensable for accurate determination of $\mathrm{W}$. Meanwhile, four-electrode probes require the $\mathrm{W}$ value for determination of $\mathrm{ECw}$ from $\mathrm{ECb}$. We present an empirical calibration method for the salinity dependence of commercial capacitance moisture probes. A four-electrode probe was also calibrated to investigate the possibility of simultaneous monitoring of $\mathrm{W}$ and $\mathrm{ECw}$ by combining each calibration equation for capacitance and four-electrode probes. A laboratory experiment was conducted using a sandy soil to obtain probe outputs at various $\mathrm{W}$ (air-dry-near-saturation) and ECw (0-31.9 $\left.\mathrm{dS} \mathrm{m}^{-1}\right)$. The output of the capacitance probe exhibited strong, nonlinear dependence on ECw. The root mean square error (RMSE) between actual W and calculated $\mathrm{W}$ using the linear functions provided by the manufacturer was at a maximum of $0.162 \mathrm{~m}^{3}$ $\mathrm{m}^{-3}$. A calibration equation, describing the probe output as a function of $\mathrm{W}$ and $\mathrm{ECW}$, was developed using curve fitting approach. The RMSE between the actual and calibrated W by this equation was at a maximum of $0.011 \mathrm{~m}^{3} \mathrm{~m}^{-3}$. The output of the four-electrode probe $(\mathrm{ECb})$ was also expressed as a function of $\mathrm{W}$ and $\mathrm{ECW}$. The calibration equations for each probe were combined and solved for $\mathrm{W}$ and ECw. Although both $\mathrm{W}$ and $\mathrm{ECW}$ were determined with acceptable accuracy, the combined calibration equation had multiple solutions for W. Development of the method to select optimal solutions will be needed for the practical application of this probe combination.
\end{abstract}

Key words: Dielectric probe, four-electrode probe, calibration, salinity, water content

\section{INTRODUCTION}

Soil water content $\left(\theta, \mathrm{m}^{3} \mathrm{~m}^{-3}\right)$ is one of the most important hydrologic variables that affects surface runoff, infiltration, evaporation and transpiration. Nondestructive monitoring methods of $\theta$ have been desired for environmental evaluation, precision agriculture and natural resources management. Widely accepted in situ methods include radioactive methods ${ }^{[13,24]}$, however, these probes cannot be left unattended and therefore it is nearly impossible to automate the measurement. Alternative techniques have been developed that take advantage of the relatively high permittivity of water to estimate $\theta$, such as Time Domain Reflectometry (TDR), impedance and capacitance methods. Every type of dielectric moisture sensor outputs an electrical signal depending on the apparent permittivity of the soil. The value of $\theta$ is empirically determined from relationships between the soil water content and electrical signals, or theoretically determined by dielectric mixing models. These dielectric moisture sensors enable nondestructive and real-time monitoring of $\theta$. However, the outputs of sensors are usually affected by soil type, salinity and temperature ${ }^{[3,29,30]}$. Therefore, calibration for these effects is essential for accurate determination of $\theta$. In this study, we focus on the dependence of the output of dielectric probes on soil salinity.

Salinity dependence of probe outputs is caused by dielectric losses of imaginary part of the complex permittivity of the soil. The dielectric losses increase with increase in ionic conductivity and with decrease in the probe frequencies ${ }^{[17]}$. Inoue et al. ${ }^{[14]}$ compared

Corresponding Author: Tadaomi Saito, Arid Land Research Center, Tottori University, 1390 Hamasaka, Tottori, Tottori, 680-0001, Japan Tel: +81-857-23-3411 Fax: +81-857-29-6199 
salinity sensitivity of twelve commercial dielectric sensors in a sandy soil and reported that the output of $\mathrm{ECH}_{2} \mathrm{O}$ EC-10 probe (Decagon Devices Inc., Pullman, Washington, USA), referred to as EC2 in their study, exhibited highest sensitivity to the electrical conductivity of the soil solution $\left(\sigma_{\mathrm{w}}, \mathrm{dS} \mathrm{m}^{-1}\right)$. The $\mathrm{ECH}_{2} \mathrm{O}$ probes employ the capacitance method and are well known as low-cost commercially available soil moisture sensors. In particular, the model EC-10 and EC-20 (hereafter referred to as ECHO10 and ECHO20, respectively) have been widely used as one of the most inexpensive soil moisture probes available ${ }^{[6,19,27]}$. The manufacturer has also recognized the salinity issue and recommended the use of these probes at $\sigma_{\mathrm{w}}$, $<0.5 \mathrm{dS} \mathrm{m}^{-1[9]}$. So far, no calibration procedure has been presented for existing ECHO10/20 users who make use of the probe in soils having $\sigma_{\mathrm{w}}>0.5 \mathrm{dS} \mathrm{m}^{-1}$. The ECHO10/20 is also known to exhibit significant temperature dependence ${ }^{[4,21]}$.

Calibration for salinity dependence is strongly recommended for every type of capacitance probe, not only for the $\mathrm{ECH}_{2} \mathrm{O}$ probes ${ }^{[12]}$. Several studies have been made on the effect of salinity for another commercial capacitance probe, the EnviroSCAN (Sentek Pty Ltd., Kent Town, South Australia) ${ }^{[3,10,28]}$. Furthermore, Kelleners et $a l^{[17,18]}$ developed a theoretical calibration method for the salinity dependence of the EnviroSCAN using an electric circuit model. Although this technique may be applicable to other capacitance probes, the theoretical calibration requires electromagnetic parameters of the probes and deep understanding of electromagnetics. It may be difficult for users themselves to apply theoretical approach for their own soils. Thus, in this study, we propose an empirical calibration method for the salinity dependence of the ECHO10/20 probe using data from a laboratory experiment. Fares et al..$^{[1]}$ developed a similar empirical approach for temperature dependence of the EnviroSCAN using a sandy soil. The first objective of this study was development of an empirical calibration equation for the salinity dependence of the ECHO10/20 probe. A calibration equation, describing the probe output as a function of $\theta$ and $\sigma_{\mathrm{w}}$, was derived for a sandy soil using curve fitting approach.

Under variable salinity conditions, the monitoring of the salinity is indispensable for the accurate determination of $\theta$ with salinity-sensitive dielectric probes. Moreover, the salinity monitoring is important for environmental evaluation and sustainable agriculture. Direct determination of $\sigma_{w}$ through the collection of soil samples and their aqueous extracts are laborious and time-consuming. Non-destructive and more practical methods are based on direct measurements of the soil bulk electrical conductivity, $\sigma_{\mathrm{b}}\left(\mathrm{dS} \mathrm{m} \mathrm{m}^{-1}\right)$, made upon geophysical-type sensors such as four-electrode probe systems, electromagnetic induction sensors and TDR systems, however, the value of $\theta$ is required for converting $\sigma_{b}$ to $\sigma_{w}$. The fourelectrode probe is inexpensive and widely used for the rapid measurement of $\sigma_{b}{ }^{[2]}$. Therefore, the simultaneous use of the dielectric probe and the four-electrode probe might be effective under variable salinity conditions because dielectric probes require the monitoring of salinity for the determination of $\theta$, while four-electrode probes require the monitoring of $\theta$ for the determination of $\sigma_{\mathrm{w}}$. It can be expected that the outputs of each probe type complement each other by combining their calibration equations. This combination of probes may become an inexpensive system that enables simultaneous monitoring of $\theta$ and $\sigma_{\mathrm{w}}$ compared with other simultaneous monitoring systems such as TDR. The newer model of $\mathrm{ECH}_{2} \mathrm{O}$ probe, ECHO-TE, also has employed this combination of system.

The second objective of this study was, therefore, to explore the possibility of simultaneous monitoring of water content and salinity by combination of the ECHO10/20 probe and the four-electrode probe. A calibration equation for the four-electrode probe, describing the probe output $\left(\sigma_{\mathrm{b}}\right)$ as a function of $\theta$ and $\sigma_{\mathrm{w}}$, was also developed for the sandy soil. This equation was combined with the calibration equation for the ECHO10/20 and solved for $\theta$ and $\sigma_{w}$.

\section{MATERIALS AND METHODS}

$\mathbf{E C H}_{2} \mathbf{O}$ soil moisture probe: The ECHO10/20 $\left(\mathrm{ECH}_{2} \mathrm{O}\right.$ model EC-10 or EC-20) probe is a plate type capacitance soil moisture sensor $(3.2 \mathrm{~cm}$ in height, 14.5 $\mathrm{cm}$ or $25.4 \mathrm{~cm}$ in length, respectively). The $\mathrm{ECH}_{2} \mathrm{O}$ probes determine the apparent permittivity of a soil by measuring the charge time of a capacitor. The measurement principle of the $\mathrm{ECH}_{2} \mathrm{O}$ probes is reported in detail by Decagon Devices, Inc. ${ }^{[8]}$. The manufacturer has provided a different linear calibration equation to describe the relationship between the output voltage, $x$ $(\mathrm{V})$ and $\theta$ for each probe model. The typical accuracy of these equations is $\pm 0.04 \mathrm{~m}^{3} \mathrm{~m}^{-3}$ in medium-textured soil types with low electrical conductivity and that they can have an accuracy of $\pm 0.02 \mathrm{~m}^{3} \mathrm{~m}^{-3}$ with a soilspecific calibration ${ }^{[9]}$. The frequency of the oscillation for the ECHO10/20 probe is $5 \mathrm{MHz}$, this low frequency is one of the reasons for high salinity sensitivity ${ }^{[8,17]}$. Recently, the manufacturer has developed new capacitance probes, the EC-5 and ECHO-TE, which 
Am. J. Environ. Sci., 4 (6): 683-692, 2008

have lower salinity sensitivity due to application of a higher frequency $(70 \mathrm{MHz})^{[5]}$.

Four-electrode Probe: A pen type four-electrode probe with a temperature sensor, SK-3100 (Sankeirika inc., Tokyo, Japan), was used in this study. The length of the sensing part is $7.5 \mathrm{~cm}$ and the diameter is $1.2 \mathrm{~cm}$. The SK-3100 probe consists of four parallel steel rings (electrodes) that constitute a Wenner-array configuration. The measurement principle of the similar four-electrode probe has been described in detail by Inoue et $a l^{[15]}$. The probe output, $\mathrm{L}_{\mathrm{t}}$, is proportional to the soil bulk electrical conductivity, $\sigma_{b}$. The proportionality constant $\left(\alpha_{\mathrm{f}}\right)$ between $\mathrm{L}_{\mathrm{t}}$ and $\sigma_{\mathrm{b}}$ is determined by measuring known electrical conductivities of various water solutions under the reference temperature. The $\alpha_{\mathrm{f}}$ value of the probe used in this study was 0.20 . While the original output of SK3100 is $\mathrm{L}_{\mathrm{t}}$, the calculated $\sigma_{\mathrm{b}}$ was adopted as the probe output hereafter in order to simplify and generalize the results.

Soil-specific calibration is required for converting $\sigma_{b}$ to the electrical conductivity of the soil solution, $\sigma_{w}$. Rhoades et $a l .{ }^{[26]}$ developed a simple and practical model to describe the relationship between $\sigma_{\mathrm{b}}$ and $\sigma_{\mathrm{w}}$. According to this model, $\sigma_{\mathrm{b}}$ at constant $\theta$ is linearly related to $\sigma_{\mathrm{w}}$ :

$$
\sigma_{\mathrm{b}}=\theta \tau \sigma_{\mathrm{w}}+\sigma_{\mathrm{s}}
$$

where, $\tau$ (non-dimensional) is a soil-specific transmission coefficient also known as tortuosity and $\sigma_{\mathrm{s}}$ is the electrical conductivity of the solid phase associated with ion exchange between the solid and liquid phases. The tortuosity can be expressed as a linear function of the water content:

$$
\tau=\mathrm{a} \theta+\mathrm{b}
$$

where, $\mathrm{a}$ and $\mathrm{b}$ are soil specific empirical constants.

Calibration Experiment: The ECHO10/20 and fourelectrode probes were calibrated in mixtures of Tottori sand (Table 1) and sodium chloride solutions. Known volumes of $\mathrm{NaCl}$ solution with known concentrations were added to the oven-dried sand to obtain desired water content and salt concentration values. In all, 35 soil samples were made with $\mathrm{NaCl}$ concentrations of $0,0.5,2.0,3.5,5,10$ and $20 \mathrm{~g} \mathrm{~L}^{-1}$ (corresponding to $\sigma_{\mathrm{w}}$ of $0,1.02,3.81,6.51,9.17,16.7$ and $31.9 \mathrm{dS} \mathrm{m}^{-1}$, respectively) and $\theta$ values of $0.046,0.122,0.183,0.274$ and $0.335 \mathrm{~m}^{3} \mathrm{~m}^{-3}$. Hereafter, these values for $\sigma_{\mathrm{w}}$ and $\theta$
Table 1: Some physical properties of Tottori sand

\begin{tabular}{lllll}
\hline $\begin{array}{l}\text { Particle } \\
\text { density } \\
\left(\mathrm{Mg} \mathrm{m}^{-3}\right)\end{array}$ & $\begin{array}{l}\text { Dry bulk } \\
\text { density } \\
\left(\mathrm{Mg} \mathrm{m}^{-3}\right)\end{array}$ & $\begin{array}{l}\text { Particle size distribution }(\%) \\
- \text { Clay }\end{array}$ & Silt & Sand \\
\hline 2.64 & 1.50 & 0 & 0 & 100 \\
\hline
\end{tabular}

are referred to as actual $\sigma_{\mathrm{w}}\left(\sigma_{\mathrm{wa}}\right)$ and actual $\theta\left(\theta_{\mathrm{a}}\right)$, respectively. The values of $\sigma_{\mathrm{wa}}$ in samples did not change by additional dissolution of salt from soils because preliminary leaching was performed sufficiently. The mixtures were kept in vinyl bags at a constant temperature of $25^{\circ} \mathrm{C}$ for two days. Then samples were packed as uniformly as possible at predetermined bulk density in covered containers (30 $\mathrm{cm}$ in length, $15 \mathrm{~cm}$ in width and height), the volumes of which were larger than the measurement volume sensed by the probes. The output value, $\mathrm{x}$ or $\sigma_{\mathrm{b}}$, was determined with the corresponding probe connected to a datalogger (Model CR-21X, Campbell Scientific, Logan, UT). Each probe was buried 5 times for each sample and the average value of the 5 outputs was used in the subsequent analysis. To avoid the inhomogeneous distribution of $\theta$ caused by downward redistribution within the sensed volume in sand, the samples were agitated sufficiently before burying the probe.

Development of Calibration Equations: A calibration equation was developed for each probe based on the results from the calibration experiment. Empirical equations were sought that can fit the data points smoothly and accurately. All curve fittings were accomplished using the Levenberg-Marquardt nonlinear method $^{[20]}$. The detailed development is shown in the Results section. In dielectric mixing models, the effect of salinity (electrolyte concentration) on the apparent soil permittivity is generally expressed as a function of $\sigma_{\mathrm{b}}$. However, we expressed the probe output of ECHO10/20 as a function of $\theta$ and $\sigma_{w}$, since the calibration equation derived as a function of $\sigma_{b}$ had non-unique solutions for $\theta$ and lower accuracy than the equation derived as a function of $\sigma_{\mathrm{w}}$. Moreover, the response of the probe output to $\sigma_{\mathrm{w}}$, which is nearly proportional to osmotic potential, may be more important and useful information than the response to $\sigma_{b}$ for users. The response of the probe output to $\sigma_{b}$ and the problem of multiple solutions for $\theta$ are discussed in the Discussion section.

\section{RESULTS}

Relationship between the output of the $\mathrm{ECH}_{2} \mathrm{O}$ probe, water content and salinity: The tendency for 

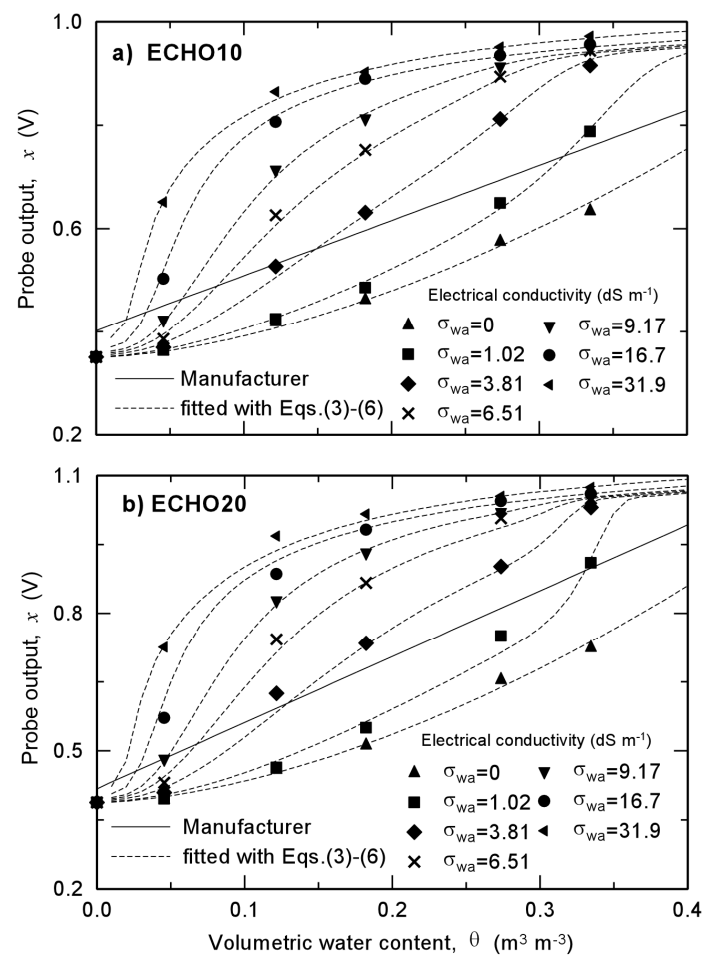

Fig. 1: Response of the probe output (x) to water content change for each electrical conductivity of the soil solution $\left(\sigma_{\mathrm{w}}\right)$ in Tottori sand. (a): ECHO10 and (b): ECHO20. The solid lines are the linear calibration functions provided by the manufacturer that neglect salinity dependence

salinity dependence of the ECHO10 was very similar to that of the ECHO20 (Fig. 1). For this reason, we will show the figures only for the ECHO10 below. All equations shown below are applicable to both the ECHO10 and ECHO20. The output of the ECHO10/20 was greatly affected by salinity: small increase in $\sigma_{\mathrm{w}}$ can drastically increase the output $(\mathrm{x})$, indicating that salinity calibrations are essential for ECHO10/20 probes when used in saline soil. For example, if the $x-\theta$ function obtained from non-saline soil were applied to saline soil with $\sigma_{\mathrm{w}}=10 \mathrm{dS} \mathrm{m} \mathrm{m}^{-1}$, the output for $\theta=0.12$ $\mathrm{m}^{3} \mathrm{~m}^{-3}$ would be misinterpreted as saturation. Linear calibration functions provided by the manufacturer did not agree with the outputs even in the low $\sigma_{\mathrm{w}}$ range. The shape of nonlinear $\mathrm{x}-\theta$ curves intricately varied with increase in $\sigma_{\mathrm{w}}$, from the convex downward to the convex upward. At high $\theta$ and $\sigma_{\mathrm{w}}\left(\theta>0.3 \mathrm{~m}^{3} \mathrm{~m}^{-3}\right.$ and $\left.\sigma_{\mathrm{w}}>6 \mathrm{dS} \mathrm{m}^{-1}\right)$ or low $\theta$ and $\sigma_{\mathrm{w}}\left(\theta<0.1 \mathrm{~m}^{3} \mathrm{~m}^{-3}\right.$ and $\sigma_{\mathrm{w}}$ $<3 \mathrm{dS} \mathrm{m}^{-1}$ ), increase in $\sigma_{\mathrm{w}}$ did not significantly increase the output. The output was also insensitive to $\theta$ in these ranges.

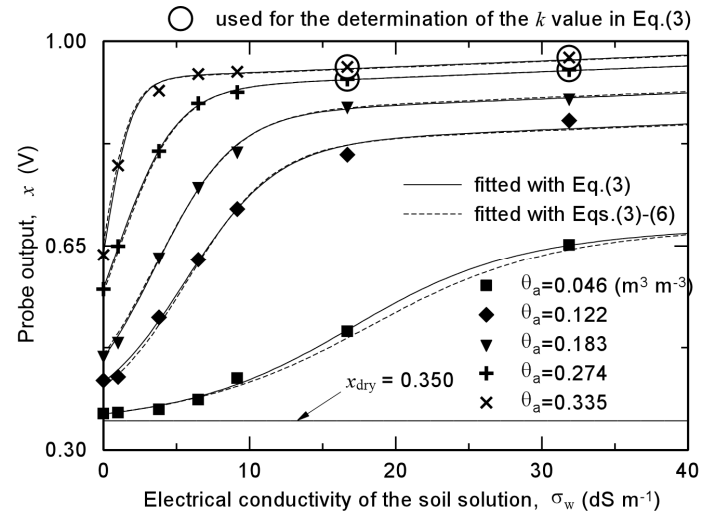

Fig. 2: Response of the output of ECHO10 probe to electrical conductivity of the soil solution for each water content in Tottori sand. The $\mathrm{x}_{\mathrm{dry}}$ is the probe output in oven-dried soil

Development and Solution of the Calibration Equation for the $\mathbf{E C H}_{2} \mathbf{O}$ probe: To develop an empirical calibration equation for the dependence of the outputs on $\theta$ and $\sigma_{\mathrm{w}}$, we sought a fitting equation that can consistently describe the $\mathrm{x}$ as a function of $\theta$ at every $\sigma_{\mathrm{wa}}$ from Fig. 1 . However, such an equation could not be found due to the irregular variation of the $\mathrm{x}-\theta$ curves with $\sigma_{\mathrm{w}}$. Thus, we sought a fitting equation for the output by replacing $\theta$ with $\sigma_{\mathrm{w}}$ on the horizontal-axis as shown in Fig. 2. Figure 2 shows the response of the output of the ECHO10 probe to $\sigma_{\mathrm{w}}$ for each water content. We fitted the outputs with a logistic curve that has an additional linear term:

$$
\mathrm{x}=\frac{\mathrm{x}_{\max }}{1+\left(\frac{\mathrm{x}_{\max }}{\mathrm{x}_{0}}-1\right) \exp \left(-\mathrm{r} \sigma_{\mathrm{w}}\right)}+\mathrm{x}_{\mathrm{dry}}+\mathrm{k} \sigma_{\mathrm{w}}
$$

where, $\mathrm{x}_{0}, \mathrm{x}_{\max }$ and $\mathrm{r}$ are coefficients of the logistic curve, $x_{\text {dry }}(\mathrm{V})$ is the output value in the oven-dried soil and $\mathrm{k}$ is the slope of the linear term. The linear term is added to improve the fit and hence to describe well the linear increase of $\mathrm{x}$ at high $\theta$ and $\sigma_{\mathrm{w}}$. Thus the value of $\mathrm{k}$ was determined at the average value of the slopes of the linear segments through two outputs at $\sigma_{\mathrm{wa}}=16.7$ and $31.9 \mathrm{dS} \mathrm{m} \mathrm{m}^{-1}$ for $\theta_{\mathrm{a}}=0.274$ and $0.035 \mathrm{~m}^{3} \mathrm{~m}^{-3}$ (Fig. 2). After determining the $\mathrm{k}$ value, the values of $\mathrm{x}_{0}$, $\mathrm{x}_{\max }$ and $\mathrm{r}$ were determined using the LevenbergMarquardt nonlinear method. Equation 3 was in excellent agreement with the outputs at every $\theta_{a}$ as shown in Fig. 2. Table 2 lists the values of $x_{\text {dry }}, k$ and root mean square errors (RMSE) of Eq. 3 for all outputs. 
Am. J. Environ. Sci., 4 (6): 683-692, 2008

Table 2: Values of $\mathrm{x}_{\mathrm{dry}}, \mathrm{k}$ and root mean square errors (RMSE) of

\begin{tabular}{|c|c|c|c|}
\hline Probe & $\mathrm{x}_{\mathrm{dry}}(\mathrm{V})$ & $\mathrm{k}$ & RMSE (V) \\
\hline$\overline{\text { ECHO10 }}$ & 0.350 & 0.0010 & 0.0060 \\
\hline ECHO20 & 0.388 & 0.0010 & 0.0096 \\
\hline
\end{tabular}

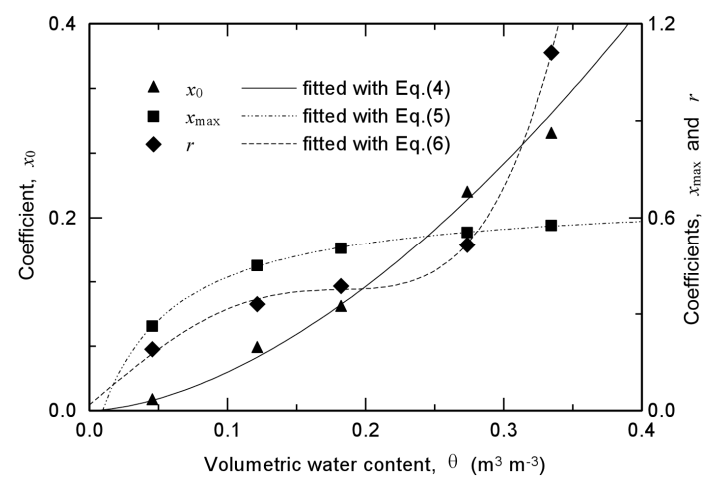

Fig. 3: Dependence of the logistic coefficients in Eq. 3 on water content for the $\mathrm{ECHO} 10$ probe

The values of the fitted coefficients, $x_{0}, x_{\max }$ and $r$, varied with $\theta_{\mathrm{a}}$. If each of these variations can be expressed as a function of $\theta$, the $\mathrm{x}$ in Eq. 3 can be expressed as a function of $\theta$ and $\sigma_{\mathrm{w}}$. The dependencies of $x_{0}, x_{\max }$ and $r$ on $\theta$ are shown in Fig. 3. The values of $\mathrm{x}_{0}, \mathrm{x}_{\max }$ and $\mathrm{r}$ were fitted with the following empirical equations, respectively:

$$
\begin{gathered}
\mathrm{x}_{0}=\mathrm{a}_{\mathrm{x} 0} \theta^{\mathrm{bx} 0} \\
\mathrm{x}_{\text {max }}=\mathrm{a}_{\mathrm{x} \max }+\frac{\mathrm{b}_{\mathrm{xmax}}}{\theta+\mathrm{c}_{\mathrm{x} \max }} \\
\mathrm{r}=\exp \left(\mathrm{a}_{\mathrm{r}} \theta+\mathrm{b}_{\mathrm{r}}\right)+\mathrm{c}_{\mathrm{r}} \sin \left(\mathrm{d}_{\mathrm{r}} \theta\right)
\end{gathered}
$$

where, $a_{x 0}, b_{x 0}, a_{x \max }, b_{x \max }, c_{x \max }, a_{r}, b_{r}, c_{r}$ and $d_{r}$ are fitting parameters. The values of the parameters and RMSE are shown in Table 3. Substituting Eq. 4-6 in Eq. 3 gives a calibration equation for the ECHO10/20 probe that expresses the dependence of probe output on $\theta$ and $\sigma_{\mathrm{w}}$. The variations of $\mathrm{x}$ calculated from Eq. 3 combined with Eq. 4-6 are shown in Fig. 1 and 2. It can be seen that this equation is still in close agreement with the data and connects data points smoothly without inappropriate fluctuations, despite its complexity.

If the value of $\sigma_{w}$ is known, the value of $\theta$ can be calibrated by solving Eq. 3 combined with Eq. 4-6 by substituting the values of $\mathrm{x}$ and $\sigma_{\mathrm{w}}$ into the equation. Since Eq. 3 can not be solved algebraically for $\theta$, a numerical root finding technique is needed: we used the bisection method. To evaluate the validity of the

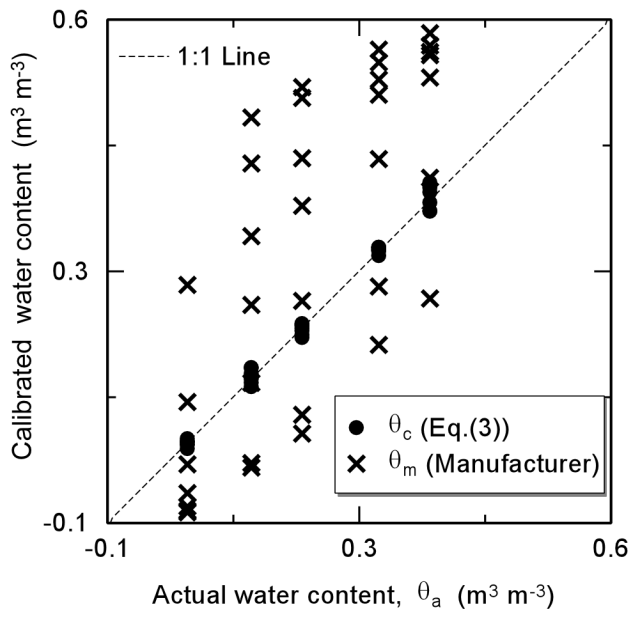

Fig. 4: Comparison of the actual and calibrated water content for the ECHO10. The $\theta_{\mathrm{c}}$ is the water content calibrated by Eq. 3. The $\theta_{\mathrm{m}}$ is the water content calibrated by the linear functions provided by the manufacturer

derived calibration equation, Eq. 3 was solved using the $\mathrm{x}$ and $\sigma_{\mathrm{wa}}$ data set from the calibration experiment. Figure 4 compares $\theta_{\mathrm{a}}$ with the calibrated water content by Eq. $3, \theta_{\text {c. }}$. Soil water content calibrated by the linear functions provided by the manufacturer $\left(\theta_{\mathrm{m}}\right)$ is also shown in Fig. 4. It can clearly be seen that Eq. 3 calibrated $\theta$ with high accuracy from low to high $\theta$ and salinity ranges. The RMSE values between $\theta_{\mathrm{a}}$ and $\theta_{\mathrm{m}}$ were $0.162 \mathrm{~m}^{3} \mathrm{~m}^{-3}$ for ECHO10 and $0.127 \mathrm{~m}^{3} \mathrm{~m}^{-3}$ for ECHO20. In contrast, the RMSE values between $\theta_{\mathrm{a}}$ and $\theta_{\mathrm{c}}$ were markedly improved: $0.008 \mathrm{~m}^{3} \mathrm{~m}^{-3}$ for ECHO10 and $0.011 \mathrm{~m}^{3} \mathrm{~m}^{-3}$ for ECHO20.

Calibration of the Four-electrode Probe: A calibration equation for the four-electrode probe, describing the probe output $\left(\sigma_{b}\right)$ as a function of $\theta$ and $\sigma_{\mathrm{w}}$, was also developed as follows. The $\sigma_{\mathrm{b}}$ was linearly related to $\sigma_{\mathrm{w}}$ at each $\theta_{\mathrm{a}}$ and was described well with Eq. 1 (Fig. 5). Each slope and intercept of the regression lines represent $\theta \tau$ and $\sigma_{\mathrm{s}}$ in Eq. 1, respectively. The dependence of the slope $(\theta \tau)$ on water content is presented in Fig. 6. The values of two fitting parameters of Eq. 2, a and b, were determined by linear regression between $\tau$ and $\theta$. However, calculated $\theta \tau$ from Eq. 2 using the determined $\mathrm{a}$ and $\mathrm{b}$ was less than zero in the low water content range $\left(\theta<0.05 \mathrm{~m}^{3} \mathrm{~m}^{-3}\right)$ as shown in Fig. 6. This causes a critical error in the determination of $\sigma_{\mathrm{w}}$, since $\sigma_{\mathrm{w}}$ has negative values when negative $\theta \tau$ values are substituted into Eq. 1. 
Am. J. Environ. Sci., 4 (6): 683-692, 2008

Table 3: Parameter values and RMSE of Eq. 4-6

\begin{tabular}{|c|c|c|c|c|c|c|c|c|c|c|c|c|}
\hline \multirow[b]{2}{*}{ Probe } & \multicolumn{3}{|c|}{ Eq. 4} & \multicolumn{4}{|c|}{ Eq. 5} & \multicolumn{4}{|c|}{ Eq. 6} & \multirow[b]{2}{*}{ RMSE } \\
\hline & $a_{x 0}$ & $b_{x 0}$ & RMSE & $a_{x \max }$ & $\mathrm{b}_{\mathrm{xmax}}$ & $c_{x \max }$ & RMSE & $\mathrm{a}_{\mathrm{r}}$ & $\mathrm{b}_{\mathrm{r}}$ & $\mathrm{c}_{\mathrm{r}}$ & $\mathrm{d}_{\mathrm{r}}$ & \\
\hline ECHO10 & 1.816 & 1.633 & 0.0091 & 0.677 & -0.034 & 0.042 & 0.0013 & 12.84 & -4.047 & -0.255 & -12.89 & 0.012 \\
\hline ECHO20 & 2.291 & 1.695 & 0.0113 & 0.767 & -0.043 & 0.049 & 0.0019 & 20.18 & -6.349 & -0.396 & -11.10 & 0.005 \\
\hline
\end{tabular}

Table 4: Parameter values and RMSE of Eq. 2, 7 and 8

\begin{tabular}{|c|c|c|c|c|c|c|c|c|c|}
\hline \multicolumn{3}{|c|}{ Eq. 2} & \multicolumn{4}{|c|}{ Eq. 7} & \multicolumn{3}{|c|}{ Eq. 8} \\
\hline $\mathrm{a}$ & $\mathrm{b}$ & RMSE & $a_{\theta \tau}$ & $b_{\theta \tau}$ & $c_{\theta \tau}$ & RMSE & $a_{\sigma s}$ & $b_{\sigma s}$ & RMSE \\
\hline 2.333 & -0.118 & 0.0051 & 0.295 & 118.879 & 17.481 & 0.0014 & 5.989 & -5.155 & 0.0004 \\
\hline
\end{tabular}

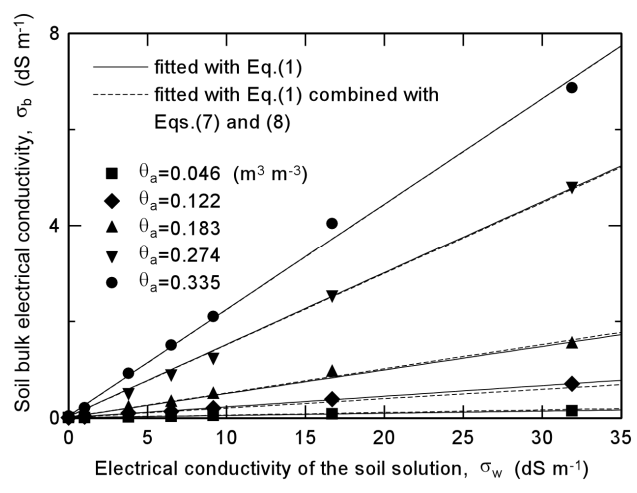

Fig. 5: Soil bulk electrical conductivity $\left(\sigma_{\mathrm{b}}\right)$ determined by the four-electrode probe as a function of the electrical conductivity of the soil solution at each water content in Tottori sand.

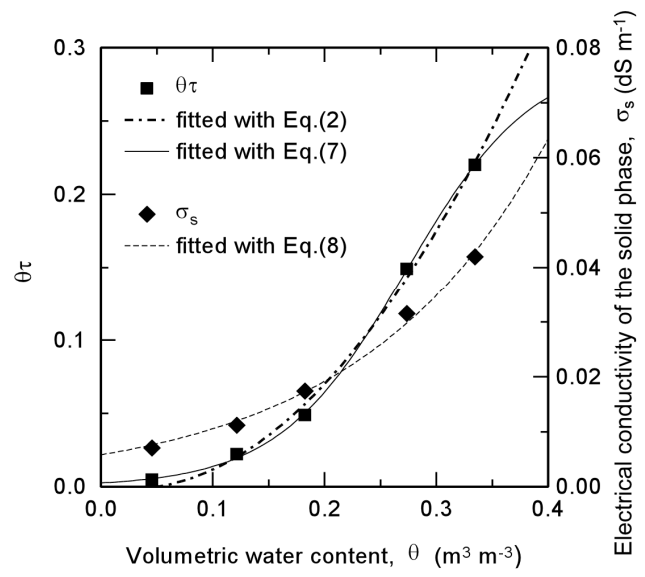

Fig. 6: Dependence of the $\theta \tau$ and electrical conductivity of the soil's solid phase $\left(\sigma_{\mathrm{s}}\right)$ on water content in Tottori sand.

Thus in this study, the $\theta \tau$ values was fitted by the following logistic curve, which provides positive $\theta \tau$ values in the low water content range:

$$
\theta \tau=\frac{\mathrm{a}_{\theta \tau}}{1+\mathrm{b}_{\theta \tau} \exp \left(-\mathrm{c}_{\theta \tau} \theta\right)}
$$

where, $a_{\theta \tau}, b_{\theta \tau}$ and $c_{\theta \tau}$ are fitting parameters.

The value of $\sigma_{\mathrm{s}}$ can be taken as zero in Eq. 1 for certain media such as Tottori sand ${ }^{[16,22]}$, however, $\sigma_{\mathrm{s}}$ and its dependence on water content was taken into account here to enhance the accuracy of determining $\sigma_{w}$ (Fig. 6). Several studies have also reported on the dependence of $\sigma_{\mathrm{s}}$ on water content ${ }^{[1,25]}$. The $\sigma_{\mathrm{s}}$ values were fitted with the following curve:

$$
\sigma_{\mathrm{s}}=\exp \left(\mathrm{a}_{\sigma \mathrm{s}} \theta+\mathrm{b}_{\sigma \mathrm{s}}\right)
$$

where, $a_{\sigma s}$ and $b_{\sigma s}$ are fitting parameters. The values of the parameters and RMSE of Eq. 2, 7 and 8 are shown in Table 4. Figure 6 shows that both $\theta \tau$ and $\sigma_{\mathrm{s}}$ were well fitted with Eq. 7 and 8. Substituting Eq. 7 and 8 into Eq. 1 gives the calibration equation describing $\sigma_{b}$ as a function of $\theta$ and $\sigma_{\mathrm{w}}$. This equation can describe the data well as shown in Fig. 5.

If the $\theta$ value is known, the $\sigma_{\mathrm{w}}$ value can be determined using Eq. 1 combined with Eq. 7 and 8 . This equation was solved algebraically for $\sigma_{\mathrm{w}}$ by substituting the $\sigma_{\mathrm{b}}$ and $\theta$ values from the calibration experiment. The comparison of $\sigma_{\mathrm{wa}}$ and the calibrated $\sigma_{\mathrm{w}}\left(\sigma_{\mathrm{wc}}\right)$ is shown in Fig. 7. The RMSE between $\sigma_{\mathrm{wa}}$ and $\sigma_{\mathrm{wc}}$ was $1.403 \mathrm{dS} \mathrm{m}^{-1}$ and the margin of relative errors in $\sigma_{\mathrm{wc}}$ for each $\sigma_{\mathrm{wa}}$ was within approximately $\pm 15 \%$.

Simultaneous Determination of Water Content and the Electrical Conductivity of Soil Solution: Substituting Eq. 1 in Eq. 3 produces a calibration equation that expresses the relationship between the ECHO10/20 probe output (x), the four-electrode probe output $\left(\sigma_{\mathrm{b}}\right)$ and water content $(\theta)$. This equation can be solved numerically for $\theta$ with the bisection method by substituting $\mathrm{x}$ and $\sigma_{\mathrm{b}}$, however, non-unique solutions were found for several combinations of $x$ and $\sigma_{b}$. Thus, in this study, the most optimal solutions were selected as $\theta_{c}$ from the obtained multiple solutions by referring the $\theta_{\mathrm{a}}$ values. The $\sigma_{\mathrm{wc}}$ values were calculated by substituting the $\sigma_{\mathrm{b}}$ and obtained $\theta_{\mathrm{c}}$ values in Eq. 1 . 


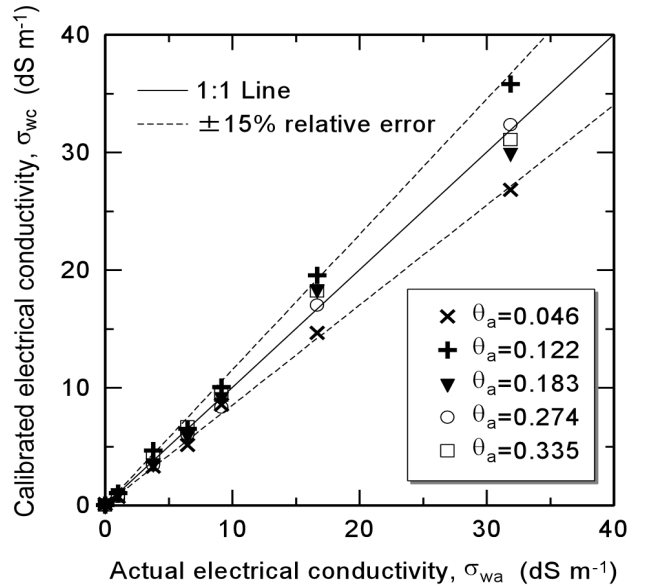

Fig. 7: Comparison of the actual and calibrated electrical conductivity of the soil solution from Eq. 1

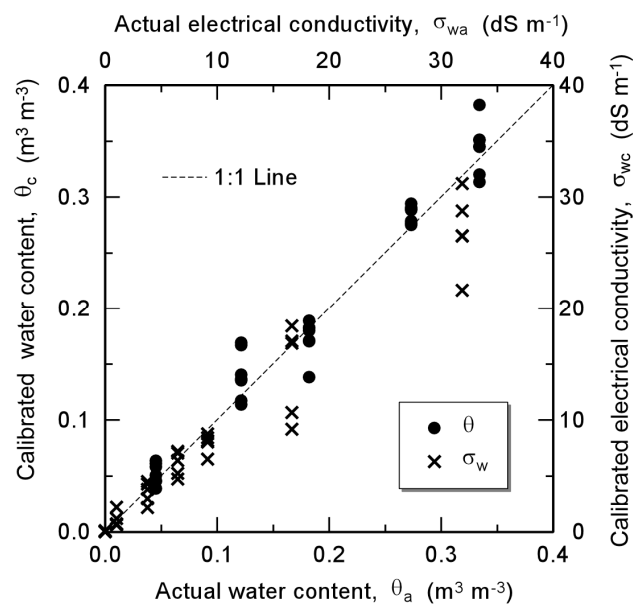

Fig. 8: Comparison of the actual and calibrated water content and electrical conductivity of the soil solution using the combined calibration equation (Eq. 3 and 1) for the ECHO10 and four-electrode probe.

Figure 8 compares $\theta_{\mathrm{a}}$ and $\theta_{\mathrm{c}}$ and $\sigma_{\mathrm{wa}}$ and $\sigma_{\mathrm{wc}}$ from Eq. 3 and 1. The RMSE between $\theta_{\mathrm{a}}$ and $\theta_{\mathrm{c}}$ was 0.019 $\mathrm{m}^{3} \mathrm{~m}^{-3}$ for the ECHO10 and $0.026 \mathrm{~m}^{3} \mathrm{~m}^{-3}$ for the ECHO20. Although the accuracy was lower than determining $\theta$ from known $\sigma_{\mathrm{w}}$ (Fig. 4), $\theta$ was calibrated with acceptable accuracy from the low to high water content range. The determination accuracy of $\sigma_{w c}$ decreased with increase in $\sigma_{\text {wa }}$. This can be basically attributed to corresponding growth in the determination error by Eq. 1) as shown in Fig. 7. The RMSE between $\sigma_{\mathrm{wa}}$ and $\sigma_{\mathrm{wc}}$ for ECHO10 and ECHO20 were 2.88 and $5.37 \mathrm{dS} \mathrm{m}^{-1}$, respectively.

\section{DISCUSSION}

Two points should be noted regarding the practical application of this combination of probes: nonuniqueness and non-existence of the solutions of the calibration equation. The calibration equation of ECHO10/20 describing $\mathrm{x}$ as a function of $\theta$ and $\sigma_{\mathrm{w}}$ (Eq. 3) had only one solution for $\theta$ in a realistic water content range (e.g., $\theta=0-0.4 \mathrm{~m}^{3} \mathrm{~m}^{-3}$ ). In contrast, the combined calibration Eq. 3 combined with Eq. 1, describing $\mathrm{x}$ as a function of $\theta$ and $\sigma_{\mathrm{b}}$, had up to three solutions in this range. The reason can be explained as follows. As shown in Fig. 2, the $\mathrm{x}-\sigma_{\mathrm{w}}$ functions at every $\theta_{\mathrm{a}}$ do not intersect each other, meaning that $\mathrm{x}$ value monotonically increases with increasing $\theta$ at any $\sigma_{w}$ values: $\theta$ has only one value for one $x$ value. In contrast, the $\mathrm{x}-\sigma_{\mathrm{b}}$ curves drawn by spline interpolation of the raw data (Fig. 9) intersect each other at several points particularly in the middle $\sigma_{\mathrm{b}}$ range, meaning that $\mathrm{x}$ value varies irregularly with $\theta$ at middle $\sigma_{\mathrm{b}}$ : $\theta$ can have multiple values for one $\mathrm{x}$ value. This suggests that a calibration equation of ECHO10/20 derived as a function of $\theta$ and $\sigma_{\mathrm{b}}$ inevitably have multiple solutions for $\theta$ due to the characteristics of the response of $\mathrm{x}$ to $\sigma_{\mathrm{b}}$, regardless of the fitting approaches and equations. Note that the complexity of the calibration equation does not cause the non-uniqueness solutions as long as the equation connects data points smoothly without inappropriate fluctuations as shown in Fig. 2.

A typical example of this non-uniqueness caused by the irregular variation of $\mathrm{x}$ with $\theta$ is shown in Fig. 10. The $x-\theta$ function had three intersections with $\mathrm{x}=0.813$. Thus, inappropriate $\theta_{\mathrm{c}}$ values may be obtained with the bisection method if the appropriate search range $\left(0.093 \mathrm{~m}^{3} \mathrm{~m}^{-3}<\right.$ for lower boundary $<0.190$ and $0.190 \mathrm{~m}^{3} \mathrm{~m}^{-3}<$ for upper boundary $<0.304$ $\mathrm{m}^{3} \mathrm{~m}^{-3}$ ) is not provided.

The non-uniqueness of solutions may severely limit the application of this approach. A possible countermeasure to this problem would be dividing the search range minutely and continuously (e.g., 0-0.05, $0.05-0.1 \ldots)$ to obtain all solutions in a realistic water content range. The optimal solution could then be selected. In actual field observations, the optimal $\theta_{c}$ may be chosen by referring to $\theta_{\mathrm{c}}$ from previous data. That is, the value of $\theta$ is extrapolated from variation of the $\theta_{\mathrm{c}}$ values at previous time steps and the closest $\theta_{\mathrm{c}}$ to the extrapolated $\theta$ is chosen as the optimal $\theta_{c}$. However, we should note that this will not apply in some situations when the logging interval is quite long or the variation of $\theta$ is large such as after heavy rainfall or 


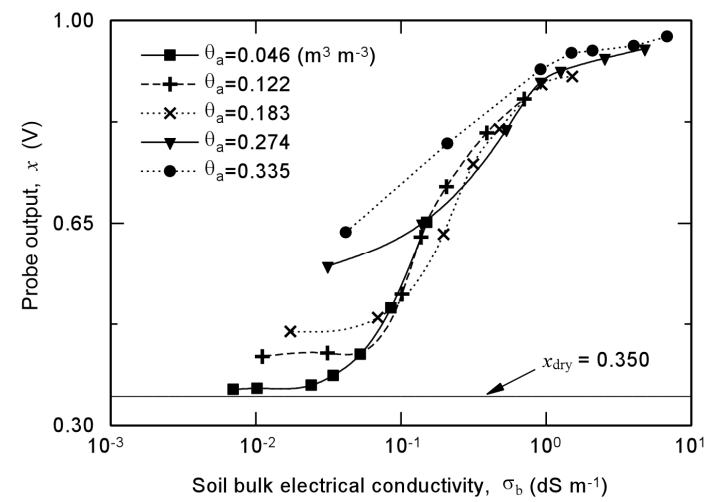

Fig. 9: Response of the output of ECHO10 probe to the soil bulk electrical conductivity for each water content in Tottori sand. The values of the bulk soil electrical conductivity were measured by a four-electrode probe. The curves were drawn by spline interpolation of the data points

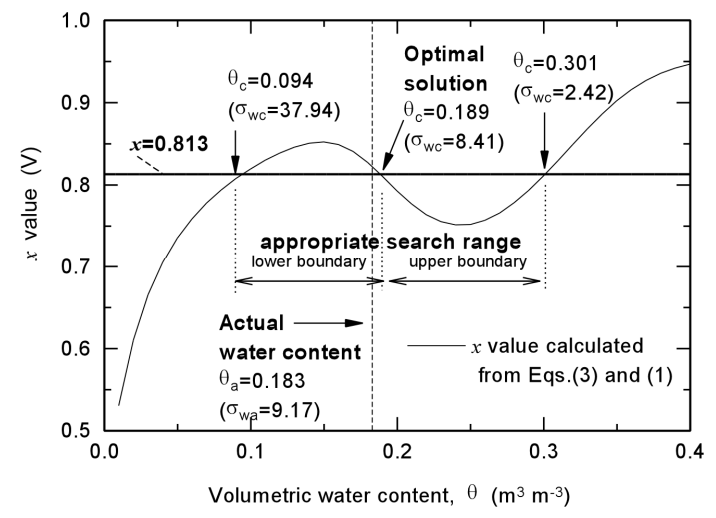

Fig. 10: Typical example of the multiple solutions of the combined calibration equation (Eq. 3 and $1)$, variation of $x$ calculated from the equation against water content change when $\theta_{\mathrm{a}}=0.183$ and $\sigma_{\mathrm{wa}}=9.17 \mathrm{dS} \quad \mathrm{m}^{-1} \quad(\mathrm{x}=0.813 \mathrm{~V}$ and $\sigma_{\mathrm{b}}=0.478 \mathrm{dS} \mathrm{m}^{-1}$ ). All of the $\theta$ values at the intersections of calculated $x$ and the line of $\mathrm{x}=0.813$ can mathematically be the solutions of the equation

irrigation events. Judging the validity of $\sigma_{\mathrm{wc}}$ values is also helpful for the selection of optimal $\theta_{\mathrm{c}}$ because $\sigma_{\mathrm{wc}}$ obtained by substituting inappropriate $\theta_{\mathrm{c}}$ in Eq. 1 can also take an inappropriate value (Fig. 10). In conclusion, the development of a flexible algorithm is needed for the automatic selection of optimal $\theta_{\mathrm{c}}$.

Decreasing the accuracy of the curve fittings leads not only to an increase in determination error of $\theta_{c}$ and $\sigma_{\mathrm{wc}}$ but also to non-existence of realistic solutions. We confirmed that when the accuracy of the derived calibration equations for ECHO10/20 and fourelectrode probes decreased slightly, the combined calibration equation had no solution or no optimal solution for some combinations of $\theta_{\mathrm{a}}$ and $\sigma_{\mathrm{wa}}$. This suggests that fitting equations as accurate as possible should be sought in deriving calibration equations. A similar problem was reported by Kelleners et al. ${ }^{[18]}$. They also found that 15 out of 88 conditions had no solution in their theoretical calibration method combining the capacitance and four-electrode probes.

Similar empirical curve fitting approaches may be applicable for other commercially available dielectric sensors including capacitance probes, considering the shapes of their output- $\sigma_{\mathrm{w}}$ curves $^{[14]}$. In particular, application to probes whose output value monotonically increases with increasing $\theta$ at any $\sigma_{\mathrm{b}}$ values seems to offer promising prospects because the problem of nonuniqueness will not arise. The combination of capacitance and four-electrode probes may be more cost effective than TDR systems. In addition, this combination seems to have an advantage over TDR under high $\sigma_{\mathrm{w}}$ conditions because TDR systems sometimes can not determine $\theta$ in high $\sigma_{\mathrm{w}}$ since the amplitude of reflected signals decreases with increase in solution concentration ${ }^{[7,23]}$.

\section{CONCLUSION}

An empirical calibration method for the salinity dependence of the ECHO10/20 probe was presented in this study. The development process of the calibration equations is summarized as the following three steps:

- Fitting $\mathrm{x}$ as a function of $\sigma_{\mathrm{w}}$ with logistic curves

- Fitting the coefficient values of the logistic curves as functions of $\theta$ with appropriate empirical equations

- Expressing $\mathrm{x}$ as a function of $\theta$ and $\sigma_{\mathrm{w}}$ by combining the fitted equations

We expect that this procedure is applicable for other types of soils. The derived equation calibrated $\theta$ with high accuracy when accurate $\sigma_{\mathrm{w}}$ values were known.

A calibration equation of a four-electrode probe was also developed to investigate the possibility of simultaneous monitoring of $\theta$ and $\sigma_{\mathrm{w}}$ by combining each calibration equation for the ECHO10/20 and fourelectrode probe. Although both $\theta$ and $\sigma_{\mathrm{w}}$ were calibrated with acceptable accuracy, the combined calibration equation had multiple solutions for $\theta$, suggesting the difficulty of simultaneous monitoring of $\theta$ and $\sigma_{\mathrm{w}}$ by this combination of probes. Development 
of a flexible algorithm may enable to select optimal solutions from multiple solutions automatically but this was not shown. In addition, we recommend that seeking fitting equations as accurate as possible in deriving calibration equations to avoid a lack of optimal solutions.

The calibration of temperature dependence of these probes is another problem. Simultaneous calibration of temperature and $\sigma_{\mathrm{w}}$ will be needed for the accurate monitoring of $\theta$ under field conditions such as in arid regions since both $\sigma_{\mathrm{w}}$ and $\sigma_{\mathrm{b}}$ are strongly affected by temperature. Further studies are anticipated to solve above problems.

Notes: The program used in this study is freely distributed under the general public license. ECH2OS, for determining water content and salinity from the outputs of ECHO10/20 probe and four-electrode probe: http://www.sakura.cc.tsukuba.ac.jp/ fujimaki/download /ECH2OS/

\section{ACKNOWLEDGEMENT}

This research was partially supported by a grant from the Global COE Program and Core University Program by Japan Society for the Promotion of Science (JSPS). TS was supported by a JSPS Research Fellowship for Young Scientists.

\section{REFERENCES}

1. Amente, G., J.M. Baker and C.F Reece, 2000. Estimation of soil solution electrical conductivity from bulk soil electrical conductivity in sandy soils. Soil Sci. Soc. Am. J., 64: 1931-1939. http://soil.scijournals.org/cgi/reprint/64/6/1931.

2. Aragüés, R., E. Playán, R. Ortiz and A. Royo, 1999. A new drip-injection irrigation system for crop salt tolerance evaluation. Soil Sci. Soc. Am. J., 63: 1397-1403. http://soil.scijournals. org/cgi/reprint/63/5/1397.

3. Baumhardt, R.L., R.J. Lascano and S.R. Evett, 2000. Soil material, temperature and salinity effects on calibration of multisensor capacitance probes. Soil Sci. Soc. Am. J., 64: 1940-1946. http://soil.scijournals.org/cgi/reprint/64/6/1940.

4. Campbell, C.S., 2006. Response of ECHO soil moisture sensor to temperature variation. Decagon Devices Inc. Application Note. Decagon Devices, Inc., Pullman, WA. http://www.decagon.com/ literature/app_notes/ResponseofECH2OSoilMoistu reSensorToTemp.pdf.
5. Campbell, C.S., G.S. Campbell and R.C. Douglas, 2005. Decreasing electrical conductivity and temperature sensitivity of a low-cost dielectric soil moisture sensor. The ASA-CSSA-SSSA International Annual Meetings, Nov. 6-10, Salt Lake City, UT., http://a-c-s.confex.com/a-cs/2005am/techprogram/P8658.HTM.

6. Christensen, N.B., 2005. Irrigation management using soil moisture monitors. Western Nutrient Manage. Conf., 6: 46-53. http://cropandsoil. oregonstate.edu/sites/default/files/WERA103/2005 _Proccedings/Christensen_Irrigation_pg46.pdf.

7. Dalton, F.N. and M.T. van Genuchten, 1986. The time-domain reflectometry method for measuring soil water content and salinity. Geoderma, 38: 237-250. http://cat.inist.fr/ ?aModele $=$ afficheN\&cpsidt $=8786557$.

8. Decagon Devices, Inc., 2006. $\mathrm{ECH}_{2} \mathrm{O}$ Dielectric Probes vs Time ime Domain Reflectometers (TDR). Decagon Devices Inc. Application Note. Decagon Devices, Inc., Pullman, Wash. http://www.decagon.com/literature/app_notes/ECH 2ODielectricProbesVsTDRProbes.pdf.

9. Decagon Devices, Inc., 2006. $\mathrm{ECH}_{2} \mathrm{O}$ Soil Moisture Sensor Operator's Manual For Models EC-20, EC-10 and EC-5 Version 5. Decagon Devices, Inc., Pullman, WA. pp: 23. http://www.decagon.com/literature/manuals/echom anual.pdf.

10. Evett, S.R., J.A. Tolk and T.A. Howell, 2006. Soil profile water content determination: sensor accuracy, axial response, calibration, temperature dependence and precision. Vadose Zone J., 5: 894-907. DOI: 10.2136/vzj2005.0149.

11. Fares, A., H. Hamdhani and D.M. Jenkins, 2007. Temperature-dependent scaled frequency: Improved accuracy of multisensor capacitance probes. Soil Sci. Soc. Am. J., 71: 894-900. DOI: 10.2136/sssaj2006.0420.

12. Fares, A. and V. Polyakov, 2006. Advances in crop water management using capacitive water sensors. Adv. Agron., 90: 43-77. http://direct.bl.uk/bld/ PlaceOrder.do?UIN=193823763\&ETOC $=$ RN\&fro $\mathrm{m}=$ searchengine.

13. Gardner, W. and D. Kirkham, 1951. Determination of soil moisture by neutron scattering. Soil Sci., 73: 391-401. http://www.osti.gov/energycitations/ product.biblio.jsp?osti_id=4385305.

14. Inoue, M., B.A. Ould Ahmed and M. Irshad, 2008. Comparison of twelve dielectric moisture probes for soil water measurement under saline conditions. Am. J. Environ. Sci., 4: 367-372. http://www. scipub.org/fulltext/ajes/ajes44367-372.pdf. 
15. Inoue, M., J. Šimůnek, S. Shiozawa and J.W. Hopmans. 2000. Simultaneous estimation of soil hydraulic and solute transport parameters from transient infiltration experiments. Adv. Water Resour., 23: 677-688. DOI: 10.1016/S03091708(00)00011-7.

16. Inoue, M. and S. Shiozawa. 1994. Measurement of electrical conductivity in soil columns by the fourelectrode method and its application. (In Japanese, with English Abstract). Soil Phys. Cond. Plant Growth Jap., 70: 23-28. http://soil.en.a.utokyo.ac.jp/jssp/db/pdf/070003.pdf.

17. Kelleners, T.J., R.W.O. Soppe, D.A. Robinson, M.G. Schaap, J.E. Ayars and T.H. Skaggs, 2004. Calibration of capacitance probe sensors using electric circuit theory. Soil Sci. Soc. Am. J., 68: 430-439. http://soil.scijournals.org/cgi/ reprint/68/2/430.

18. Kelleners, T.J., R.W.O. Soppe, J.E. Ayars and T.H. Skaggs, 2004. Calibration of capacitance probe sensors in a saline silty clay soil. Soil Sci. Soc. Am. J., 68: 770-778. http://soil.scijournals.org/cgi/reprint/68/3/770.

19. Luedeling, E., M. Nagieb, F. Wichern, M. Brandt, M. Deurer and A. Buerkert, 2005. Drainage, salt leaching and physico-chemical properties of irrigated man-made terrace soils in a mountain oasis of northern Oman. Geoderma, 125: 273-285. DOI: 10.1016/j.geoderma.2004.09.003.

20. Marquardt, D.W., 1963. An algorithm for leastsquares estimation of nonlinear parameters. SIAM J. Appl. Math, 11: 431-441. http://www.jstor.org/pss/2098941.

21. McMichael, B. and R. J. Lascano, 2003. Laboratory evaluation of a commercial dielectric soil water sensor. Vadose Zone J., 2: 650-654. http://vzj.scijournals.org/cgi/reprint/2/4/650.

22. Muñoz-Carpena, R., C.M. Regalado, A. Ritter, J. Alvarez-Bened ${ }^{\prime}$ and A.R. Socorro, 2005. TDR estimation of saline solutes concentration in a volcanic soil. Geoderma, 124: 399-413. DOI: 10.1016/j.geoderma.2004.06.002.
23. Noborio, K., 2001. Measurement of soil water content and electrical conductivity by time domain reflectometry: A review. Comput. Elect. Agron., 31: 213-237. DOI: $10.1016 /$ S01681699(00)00184-8.

24. Reginato, R.J. and C.H.M. van Bavel, 1964. Soil water measurement with gamma attenuation. Soil Sci. Soc. Am. Proc., 28: 721-724. http://soil.scijournals.org/cgi/reprint/28/6/721.

25. Rhoades, J.D., N.A. Manteghi, P.J. Shouse and W.J. Alves, 1989. Soil electrical conductivity and soil salinity: New formulations and calibrations. Soil Sci. Soc. Am. J., 53: 433-439. http://soil.scijournals.org/cgi/reprint/53/2/433.

26. Rhoades, J.D., P.A. Ratts and R.J. Prather, 1976. Effects of liquid-phase electrical. conductivity, water content and surface conductivity on bulk soil electrical. conductivity. Soil Sci. Soc. Am. J., 40: 651-655. http://soil.scijournals.org/cgi/reprint/ 40/5/651.

27. Riley, T.C., T.A. Endreny and J.D. Halfman, 2006. Monitoring soil moisture and water table height with a low-cost data logger. Comput. Geosci., 32: 135-140. DOI: 10.1016/j.cageo.2005.05.009.

28. Schwank, M. and T. R. Green, 2007. Simulated effects of soil temperature and salinity on capacitance sensor measurements. Sensors, 7: 548-577. http://www.mdpi.org/sensors/papers/ s7040548.pdf.

29. Topp, G.C., J.L. Davis and A.P. Annan, 1980. Electromagnetic determination of soil water content: measurements in coaxial transmission lines. Water Resour. Res., 16: 574-582. http://www.agu.org/pubs/crossref/1980/WR016i00 3p00574.shtml.

30. Wraith, J.M. and D. Or, 1999. Temperature effects on soil bulk dielectric permittivity measured by time domain reflectometry: Experimental evidence and hypothesis development. Water Resour. Res., 35: 361-369. http://www.agu.org/pubs/crossref/ 1999/1998WR900006.shtml. 